\title{
Organizational Behavior: The Investigation of Communications Effectiveness \& Emotional Intelligence on Job Satisfaction (Case Study in Iran's Universities)
}

\author{
Hassan Jorfi ${ }^{1}$, Mahdi Elhaee Sahar ${ }^{2}$, Mohsen Jorfi ${ }^{3}$, Gholamhosien Ebadi ${ }^{4}$ \\ ${ }^{1} \mathrm{Ph} . \mathrm{D}$. Student Department of Accounting, Islamic Azad University, Sousangerd Branch, Iran. \\ ${ }^{2}$ Student Department of Accounting, Islamic Azad University, Sousangerd Branch, Iran. \\ ${ }^{3}$ Student Department of Counseling,Islamic Azad University, Kerman Branch, Iran \\ ${ }^{4}$ Ph.D. Student Department of Psychometric Scientific Board Member and Chairman of the Institute \\ of Education in Khuzestan Province, Iran
}

\begin{abstract}
In today's complex global environment, communications effectiveness and emotional intelligence remains a key topic of concern among managers worldwide. The paper is undertaken to understand the relationship between managers' communications effectiveness to improve emotional intelligence and job satisfaction in the universities of Iran. In current paper emotional intelligence plays main role in relationship with communication effectiveness and with job satisfaction. Data $(\mathrm{N}=234)$ for this study were collected through questionnaires and the participants were managers in universities of Iran. The result in current paper shows that emotional intelligence has a positive and strong relationship with communication effectiveness and with job satisfaction.
\end{abstract}

Keywords: Communications Effectiveness, Emotional Intelligence, Job Satisfaction.

\section{INTRODUCTION}

By reviewing the existing literature, the researcher aims at identifying some relationships, and introducing the findings as the conceptual model. On the other hand, Communication plays an important role in the management of professional organizations and their achievement of success. Communication effectiveness has long been held to be a success factor for managers. Effective communication can add value to organizations [7]. Fisher states that communication effectiveness is a vital factor in the workplace, in relationships, and in everyday life [6]. Communication effectiveness in organizations can unite the managers, workers, decision making, and improve teamwork [7]. Results of these studies indicated that emotional intelligence played a pivotal role in human communication. The need to establish the relationship between emotional intelligence (EI) and effective communication was recognized. This relationship was further emphasized by many EI theorists who asserted that managers who are emotionally intelligent communicate well with people ([8], [9], [10]).

\subsection{Emotional Intelligence}

Mayer, Salovey and Caruso, defined EI as "the ability to perceive emotions, to access and generate emotions so as to assist thought, to understand emotions and emotional knowledge, and to reflectively regulate emotions so as to promote emotional and intellectual growth" [12]. Also, Esther Orioli and Robert Cooper defined EI as "ability to sense, understand, and effectively apply the power and acumen of emotions as a source of human energy, information, trust, creativity and influence" [11].

\subsection{Job Satisfaction}


Job satisfaction is vital in the day to day life, which is far past the studies and literature related to research. Job satisfaction can be defined as an encouraging emotional condition as a result from the features and characteristics of a work environment ([15], [16]). Organizations produce noteworthy effects on their employees and a number of those effects are indicated in how people feel about their jobs [17]

\subsection{Communication Effectiveness}

According to Campbell communicative effectiveness is deliberate behavior aimed at augmenting the result of an interpersonal meeting [5]. Similarly, the expression "communication effectiveness" is often replaced by, "effective communication" ([2], [3], [4]). In other words, communication becomes valuable and effective when the people involved in the communication can augment understandings and decrease misunderstandings. In the study, communication effectiveness includes: skill, motivation, and knowledge, that these dimensions have direct relationship with job satisfaction. Locke proposed these steps (motivation, knowledge and skill) for achieving communication effectiveness and competence in the organizations. Motivation occurred through challenging biased assumptions; knowledge occurred through presenting virtual knowledge and information about a special process; and skill occurred through recognizing correct events based on suitable awareness and precise knowledge [1].

\subsection{Emotional intelligence and communication effectiveness}

Main advocators of emotional intelligence theory argue that emotional intelligence lead to improve communication effectiveness in messages ([13], [9]). Bar-On "to be emotionally and socially intelligent is to effectively understand and express oneself, to understand and relate well with others, and to successfully cope with daily demands, challenges, and pressures." (p. 3). [14].

\subsection{Emotional intelligence and job satisfaction}

There are some studies have examined the connections between emotional intelligence and job satisfaction. Organization managers in the 21st century tend to provide educational facilities for their employees so that they improve their physical, psychological, emotional and mental capabilities [18] is why emotional aspect of employees should be emphasized in addition to cognitive aspect. Emotional intelligence can create a pleasant workplace and affect employees` job satisfaction, efficient management and organization development [19].

\section{CONCEPTUAL FRAMEWORK}

The model for this paper is composed of three key constructs (see Figure1) including communications effectiveness, emotional intelligence, and job satisfaction. Based on the existing literature-as stated earlier- there is a positive relationship between emotional intelligence and communication effectiveness and job satisfaction.

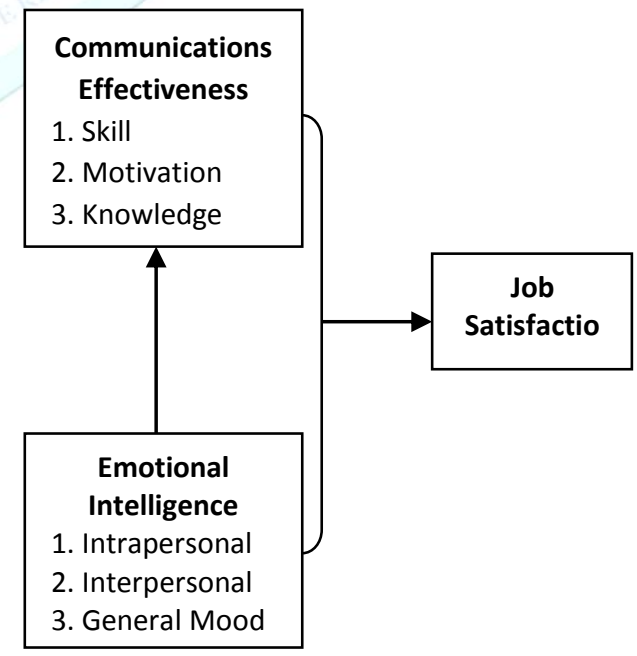

Figure 1: Conceptual Framework

From the model, the following hypothesis is derived:

- H1: Communications effectiveness will have a significant relationship with job satisfaction. 
- H1a: Skill will have a significant relationship with job satisfaction.

- H1b: Motivation will have a significant relationship with job satisfaction.

- H1c: Knowledge will have a significant relationship with job satisfaction.

- H2: Emotional intelligence will have a significant relationship with job satisfaction.

- H2a: Intrapersonal will have a significant relationship with job satisfaction.

- H2b: Interpersonal will have a significant relationship with job satisfaction.

- H2c: General Mood will have a significant relationship with job satisfaction.

- H3: Emotional intelligence will have a significant relationship with communication effectiveness.

- H3a: Intrapersonal will have a significant relationship with communication effectiveness.

- H3b: Interpersonal will have a significant relationship with communication effectiveness.

- H3c: General Mood will have a significant relationship with communication effectiveness.

\section{OUTCOMES \& DISCUSSION}

Communications effectiveness and emotional intelligence are independent variables in this research and job satisfaction in universities of Iran is considered as the dependent variable. The present research is an applicable one with interrelationship. The researcher tries to investigate a connection between variables. The purpose of this applied study and correlation in this research is the assessment of this connection between variables and making on these predictions the researcher looks for a probable relation between communications effectiveness, emotional intelligence, and job satisfaction. Statically group consists of 234 subjects sample volume of about 456 people. Libraries have been used to collect data; sources like: books, journals, magazines, newspapers, scientific reports, organizations archives, field studies and questionnaire by making use of evaluated specter of Likerts' spectrum. For hypothesis test first the average of questions selected to each variables were specified then the software package (SPSS, Ver16) analyzed the connections between both groups of variables. The validity of the questionnaire was evaluated by Cronbach' alpha is formula for measuring the amount of which was $78 \%$ which is acceptable. The consistency of the questionnaire was announced by seven authorities at the average at $95 \%$. Kendall's coefficient of concordance's method was used to analyze and explain the present research. Based on analyzed via Kendall's coefficient of concordance by the use of (SPSS, Ver16) was performed the results given below were obtained:

H1: Kendal's coefficient between major variables (communications effectiveness) and dependent variable (job satisfaction) is equal to $86 \%$ and there is significantly positive correlation between two variables considering the fact that a rate of 0.999 is significant.

H1a: there is a significant relationship between the skill of communication effectiveness and job satisfaction. The correlation coefficient is 0.69 out a significant level of 0.999 , thus, the first hypothesis has been validated.

$\mathrm{H} 1 \mathrm{~b}$ : there is a significant relationship between motivation of communications effectiveness and job satisfaction. The correlation coefficient is 0.86 , thus, the second hypothesis has been validated.

H1c: there is a significant relationship between knowledge of communications effectiveness and job satisfaction. The correlation coefficient is 0.66 , thus, the third hypothesis has been validated.

H2: Kendal's coefficient between major variables (emotional intelligence) and job satisfaction is equal to $88 \%$ and there is significantly positive correlation between two variables considering the fact that a rate of 0.999 is significant.

$\mathrm{H} 2 \mathrm{a}$ : there is a significant relationship between intrapersonal and job satisfaction. The correlation coefficient is 0.79 out a significant 
level of 0.999 , thus, the first hypothesis has been validated.

$\mathrm{H} 2 \mathrm{~b}$ : there is a significant relationship between interpersonal and job satisfaction. The correlation coefficient is 0.80 , thus, the second hypothesis has been validated.

$\mathrm{H} 2 \mathrm{c}$ : there is a significant relationship between general mood and job satisfaction. The correlation coefficient is 0.66 , thus, the third hypothesis has been validated.

H3: Kendal's coefficient between major variables (emotional intelligence) and communication effectiveness is equal to $89 \%$ and there is significantly positive correlation between two variables considering the fact that a rate of 0.999 is significant.

H3a: there is a significant relationship between intrapersonal and communication effectiveness. The correlation coefficient is 0.81 out a significant level of 0.999 , thus, the first hypothesis has been validated.

$\mathrm{H} 3 \mathrm{~b}$ : there is a significant relationship between interpersonal and communication effectiveness. The correlation coefficient is 0.78 , thus, the second hypothesis has been validated.

$\mathrm{H} 3 \mathrm{c}$ : there is a significant relationship between general mood and communication effectiveness. The correlation coefficient is 0.75 , thus, the third hypothesis has been validated.

\section{CONCLUSION}

Over results have shown there is a significant and positive relationship between independent variables communication effectiveness (i.e. skill, knowledge, and motivation) and emotional intelligence (i.e. intrapersonal, interpersonal, and general mood) with dependent variable (job satisfaction) in universities of Iran. From the results of the study, we can conclude that the universities of Iran should pay much attention to communications effectiveness and emotional intelligence as they could lead to maintain job satisfaction. We encourage future research to replicate our findings in wider samples in organizations of Iran. It is important to note that prior researches have ignored the link between communication effectiveness and emotional intelligence and communication effectiveness; that the current study was developed with the intention of filling the research gap

\section{REFERENCES}

[1] E. Locke, "The nature and causes of job satisfaction. In M. D. Dunnette" (Ed.), Handbook of industrial and organizational psychology Chicago: Rand McNally, 1976, pp. 1297-1349.

[2] W.B. Gudykunst, "Toward a theory of effective interpersonal and intergroup communication: An anxiety/uncertainty management perspective", In R. L. Wiseman, \& J. Koester (Eds.), Intercultural communication competence. Newbury Park: CA: Sage, 1993, pp. 33-71.

[3] W.B. Gudykunst, "Anxiety/uncertainty management (AUM) theory: Current status", In R. L. Wiseman (Ed.), Intercultural communication theory Thousand Oaks, CA: Sage, 1995, pp. 858

[4] W.B. Gudykunst, "An anxiety/uncertainty management (AUM) theory of effective Communication: Making the mesh of the net finer", In W. B. Gudykunst (Ed.), Theorizing about intercultural communication, Thousand Oaks, CA: Sage, 2005a, pp. 281-322.

[5] D. G. Campbell, "An empirical comparison of three theories of decent ring", Dissertation Abstracts International, vol. 50 (12), 1989, 37924320, (UMI No. 9012890).

[6] H. Fisher, "The first sex: The natural talents of women and how they are changing the world", New York: Ballantine Books, 1999.

[7] H. Thamhain, "Engineering management: Managing effectively in technology-based organizations", New York: John Wiley \& Sons, 1992.

[8] D. Goleman, "Emotional Intelligence", Bantham, New York, NY, 1995.

[9] J.D.Mayer, P. Salovey, \& D.R. Caruso, "Emotional intelligence: Theory, findings, and implications" 
Psychological Inquiry, vol. 15, pp.197215, 2004.

[10] H. Weisinger, "Emotional intelligence at work: The untapped edge for success", San Francisco: Jossey-Bass, 1998.

[11] E.M. Oriole \& R.K. Cooper, "EQ-Map: Interpretation Guide. An integrated EQ assessment and individual profile", San Francisco, CA: Essi System, Inc, 1997.

[12] J. D. Mayer, \& P. Salovey, The intelligence of emotional intelligence. Intelligence", vol. 17, pp. 433-442, 1997.

[13] D. Goleman, "What makes a leader"?, Harvard Business Review, NovemberDecember, 1998b.

[14] R. Bar-On, "EQ-I BarOn Emotional Quotient Inventory: Technical Manual”,
Toronto, Canada: Multi-Health Systems, 2002.

[15] Arches, J. (1991). Social structure, burnout, and job satisfaction. Social Work, 36, 193-272.

[16] Dressel, P.L. (1982). Policy sources of worker dissatisfaction: The case of human services in aging. Social Service Review, 56, $406-423$.

[17] Spector, P.E. (1997), Job Satisfaction, Sage, Thousand Oaks, CA.

[18] Ashkanasy, N. M., \& Dasborough, M. T. (2003). Emotional awareness and emotional intelligence in leadership teaching. Journal of Education for Business, 9, 18-22.

[19] Patra, S., (2004). Role of emotional intelligence in educational management. J. Indian Educ., 30(1): 98-104. 